\title{
Emended description of Yersinia massiliensis
}

Correspondence

Juliana P. Falcão

jufalcao@fcfrp.usp.br

\author{
Roberto A. Souza, ${ }^{1}$ Deise P. Falcão ${ }^{2}$ and Juliana P. Falcão ${ }^{1}$ \\ ${ }^{1}$ Brazilian Reference Center on Yersinia spp. other than Y. pestis, Departamento de Análises \\ Clínicas, Toxicológicas e Bromatológicas, Faculdade de Ciências Farmacêuticas de Ribeirão Preto \\ - USP, Ribeirão Preto, Brazil \\ ${ }^{2}$ Departamento de Ciências Biológicas, Faculdade de Ciências Farmacêuticas de Araraquara - \\ UNESP, Araraquara, Brazil
}

\begin{abstract}
The bacterial genus Yersinia belongs to the family Enterobacteriaceae and comprises 15 species. Species of the genus Yersinia are usually identified by their phenotypic characteristics. Thus, it is essential to establish a complete phenotypic classification for all species of the genus Yersinia. The species Yersinia massiliensis was proposed in 2008, based on 16S rRNA, gyrB, hsp60, $r p o B$ and sod $A$ gene sequences and some distinguishing phenotypic characteristics. In this study, four Yersinia strains classified as $Y$. massiliensis based on the sequencing of the loci mentioned above were subjected to a more detailed phenotypic characterization. This characterization revealed differences in the results of four tests previously reported as diagnostic for $Y$. massiliensis and the results of 18 additional tests provided new information about the biochemical diversity of this species. In the light of the results of the phenotypic characteristics of the four strains of $Y$. massiliensis, an emended description of $Y$. massiliensis is presented.
\end{abstract}

The bacterial genus Yersinia belongs to the family Enterobacteriaceae and comprises 15 recognized species. Yersinia pestis, Yersinia pseudotuberculosis and Yersinia enterocolitica are associated with human and animal diseases. Yersinia ruckeri is a fish pathogen and all the other species are considered to be mainly non-pathogenic and environmental isolates (Wanger, 2007). The newest members of the genus are Yersinia aleksiciae (Sprague \& Neubauer, 2005), Yersinia similis (Sprague et al., 2008), Yersinia massiliensis (Merhej et al., 2008) and Yersinia entomophaga (Hurst et al., 2011).

Four $Y$. massiliensis strains selected from the collection of the Brazilian Reference Center on Yersinia spp. other than $Y$. pestis shared many of the phenotypic characteristics with strain CCUG $53443^{\mathrm{T}}$, the type strain of $Y$. massiliensis. However, they differed from this type strain in the results of four biochemical tests used to characterize this species, as described in Merhej et al. (2008). Further information on the four Y. massiliensis strains used in this study is given in Table 1. It is important to highlight that these Yersinia strains had been isolated from environmental and food sources and had not been implicated in human disease.

The four strains, FCF 216, FCF 465, FCF 457 and FCF 494, were assigned as belonging to the species $Y$. massiliensis based on the sequences of five conserved loci (16S rRNA,

The GenBank/EMBL/DDBJ accession numbers for the 16S rRNA, $\operatorname{gyr} B, h s p 60, r p o B$ and $\operatorname{sod} A$ gene sequences described in this study are GQ421616-GQ421635.

Supplementary figures are available with the online version of this paper.
gyrB, hsp60, rpoB and sodA gene sequences). Internal fragments of these loci were amplified for the four strains and were compared with sequences of the same loci for other species of the genus Yersinia that had already been deposited in GenBank (Kotetishvili et al., 2005; Sprague \& Neubauer, 2005; Merhej et al., 2008; Sprague et al., 2008; Hurst et al., 2011). The sequence and phylogenetic analyses were performed as described by Souza et al. (2010). Phylogenetic trees constructed from the 16S rRNA gene sequences and also from a 'super locus' consisting of the concatenated $g y r B, h s p 60, r p o B$ and $\operatorname{sod} A$ sequences for each strain are available as supplementary data with the online version of this paper (Supplementary Figs S1 and S2 in IJSEM Online).

In order to elucidate the phenotypic diversity of $Y$. massiliensis species, strains FCF 216, FCF 465, FCF 457, FCF 494 and CCUG $53443^{\mathrm{T}}$ were subjected to a battery of phenotypic tests. The strains were reisolated on MacConkey agar (Acumedia). They were subjected to the phenotypic tests shown in Table 2. Carbohydrate fermentation and citrate utilization were carried out at $28{ }^{\circ} \mathrm{C}$ for 7 days. The other tests were performed at $28{ }^{\circ} \mathrm{C}$ for $48 \mathrm{~h}$. The motility assay was conducted at $28{ }^{\circ} \mathrm{C}$ and $37{ }^{\circ} \mathrm{C}$ for $48 \mathrm{~h}$. Oxidase activity was detected by using a dimethyl$p$-phenylenediamine oxalate disk (Newprov). Catalase activity was detected by emulsifying a colony in $3 \%$ hydrogen peroxide and checking for the presence of bubbles. Other tests, such as citrate utilization (Acumedia), phenylalanine deaminase (Difco) and urea hydrolysis (Acumedia) were performed according to the manufacturers' instructions. 
Table 1. Summary of some characteristics of the four $Y$. massiliensis strains used in this study

\begin{tabular}{|lllll|}
\hline Strain & \multicolumn{1}{c}{ Source } & Country & Year & Serogroup $^{\star}$-phage typed $\dagger$ \\
\hline Y. massiliensis FCF 216 & Water & Brazil & 1984 & O:10-Xz \\
Y. massiliensis FCF 465 & Water & Argentina & 1990 & O:10, 34-Xo \\
Y. massiliensis FCF 457 & Pasteurized milk & Brazil & 1990 & O:22-Xo \\
Y. massiliensis FCF 494 & Lettuce & Brazil & 1991 & O:10, 34-Xo \\
\hline
\end{tabular}

${ }^{*}$ According to Wauters et al. (1991).

$\dagger$ According to Nicolle et al. (1976).

Carbohydrate fermentation was conducted as described in MacFaddin (2000) using each carbohydrate at a concentration of $0.5 \%$, with the exception of methyl $\alpha$-Dglucoside, which was used at $1.0 \%$. Gas from glucose and $\mathrm{H}_{2} \mathrm{~S}$ production were observed in triple-sugar iron agar (HiMedia Laboratories), according to the manufacturer's instructions. The other tests were all prepared in house. Nitrate reduction, Voges-Proskauer reaction, indole production, ornithine decarboxylase, lysine decarboxylase, arginine dihydrolase and motility tests were prepared as reported in MacFaddin (2000). Salicin fermentation and

Table 2. Comparison of phenotypic characteristics between $Y$. massiliensis strains FCF 216, FCF 465, FCF 457, FCF 494 and $Y$. massiliensis CCUG $53443^{\top}$

Data for strain CCUG $53443^{\mathrm{T}}$ are from Merhej et al. (2008). Tests for L-rhamnose, melibiose, methyl $\alpha$-D-glucoside ${ }^{\star}$ fermentation, oxidase, gas from glucose $e^{\star}$, Voges-Proskauer, $\mathrm{H}_{2} \mathrm{~S}$ production ${ }^{\star}$, lipase ${ }^{\star}$, gelatin hydrolysis and motility at $37{ }^{\circ} \mathrm{C}^{*}$ were negative for all five strains. Tests for cellobiose $e^{\star}$, sucrose, trehalose ${ }^{\star}$, L-sorbose $^{*}$, D-sorbitol, maltose ${ }^{\star}$, L-fucose ${ }^{\star}$, salicin ${ }^{\star}$, inositol, L-arabinose, D-xylose ${ }^{\star}$, D-mannitol fermentation, mucate utilization ${ }^{*}$, nitrate reduction ${ }^{\star}$, indole production, ornithine decarboxylase, pyrazinamidase production ${ }^{\star}$, urea hydrolysis, aesculin hydrolysis ${ }^{\star}$, catalase and motility at $28{ }^{\circ} \mathrm{C}$ were positive for all five strains. + , Positive; - , negative; ND, not done. For carbohydrate fermentation and citrate utilization tests, incubation was performed at $28{ }^{\circ} \mathrm{C}$ for 7 days. For the remaining tests, incubation was conducted at $28{ }^{\circ} \mathrm{C}$ for $48 \mathrm{~h}$. ${ }^{*}$ Additional tests performed in this study.

\begin{tabular}{|lccccc|}
\hline Characteristic & CCUG $^{2}$ & FCF & FCF & FCF & FCF \\
& $5^{2} \mathbf{4 4 3}^{\text {T }}$ & $\mathbf{2 1 6}$ & $\mathbf{4 6 5}$ & $\mathbf{4 5 7}$ & $\mathbf{4 9 4}$ \\
\hline Lactose fermentation & $\mathrm{ND} \dagger$ & - & + & + & - \\
Raffinose & $\mathrm{ND} \dagger$ & - & - & + & - \\
$\quad$ fermentation & & & & & \\
Citrate utilization & + & - & - & - & + \\
Lysine decarboxylase & $+\dagger$ & - & - & - & - \\
Arginine dihydrolase & $+\dagger$ & - & - & - & - \\
$\begin{array}{l}\text { Phenylalanine } \\
\text { deaminase }\end{array}$ & $+\dagger$ & - & - & - & - \\
& & & & & \\
\hline
\end{tabular}

$\dagger$ Data shown are from Merhej et al. (2008). These tests were negative under our conditions of incubation at $28{ }^{\circ} \mathrm{C}$ for $48 \mathrm{~h}$. aesculin hydrolysis were performed as reported in Farmer et al. (1992). Gelatin hydrolysis and lipase were carried out according to the methods of Dempsey \& Kitting (1987). Mucate utilization and pyrazinamidase production were conducted as described by the US Food and Drug Administration (2010) and Kandolo \& Wauters (1985), respectively.

In order to perform a more detailed phenotypic characterization of the species $Y$. massiliensis, the following tests were performed in addition to those previously conducted by Merhej et al. (2008): lactose, raffinose, methyl $\alpha$-D-glucoside, cellobiose, D-trehalose, L-sorbose, maltose, L-fucose, salicin and D-xylose fermentation, plus gas from glucose, $\mathrm{H}_{2} \mathrm{~S}$ production, mucate utilization, nitrate reduction, pyrazinamidase production, lipase, aesculin hydrolysis and motility at $37^{\circ} \mathrm{C}$.

The results of the tests on strains FCF 216, FCF 465, FCF 457 and FCF 494 are summarized in Table 2 and are compared with the phenotypic characteristics of $Y$. massiliensis CCUG $53443^{\mathrm{T}}$ as proposed by Merhej et al. (2008). The results of three biochemical tests reported by Merhej et al. (2008) for $Y$. massiliensis were significantly different from those obtained for the $Y$. massiliensis strains in this study. Y. massiliensis strains CCUG $53443^{\mathrm{T}}$ and CCUG 53444 were reported as positive in tests for lysine decarboxylase, arginine dihydrolase and phenylalanine deaminase by Merhej et al. (2008), but the four strains from our collection gave negative results. However, under our conditions of incubation at $28{ }^{\circ} \mathrm{C}$ for $48 \mathrm{~h}, Y$. massiliensis CCUG $53443^{\mathrm{T}}$ showed negative results for the lysine decarboxylase, arginine dihydrolase and phenylalanine deaminase reactions.

As described by Bottone et al. (2005), all species of the genus Yersinia are lysine decarboxylase-, phenylalanine deaminase- and arginine dihydrolase-negative. However, Bottone et al. (2005) and Sprague \& Neubauer (2005) have reported lysine decarboxylase activity in $Y$. aleksiciae and in some strains of $Y$. ruckeri, $Y$. kristensenii and $Y$. intermedia. Farmer et al. (1985) reported that a small number of $Y$. ruckeri strains were arginine dihydrolase-positive.

In this study, variable results were also found for citrate utilization. Specifically, three of the $Y$. massiliensis strains (FCF 216, FCF 465 and FCF 457) gave negative results for 
citrate utilization and only strain FCF 494 was able to utilize citrate. Citrate utilization was reported as positive for Y. massiliensis strains CCUG $53443^{\mathrm{T}}$ and CCUG 53444 by Merhej et al. (2008).

It is suggested that the phenotypic differentiation of $Y$. massiliensis from other species of the genus Yersinia should not just be based on the phenotypic tests proposed by Bockemühl \& Wong (2003), Ewing et al. (1978), Sprague \& Neubauer (2005), Sprague et al. (2008) and Hurst et al. (2011). Y. enterocolitica, Y. kristensenii, Y. aleksiciae, $Y$. rohdei and $Y$. mollaretii differ from $Y$. massiliensis by the result of only a single test. Thus, it could be possible to identify these species incorrectly. To avoid this problem, we suggest adding aesculin hydrolysis and mucate utilization to the phenotypic identification of species of the genus Yersinia, as presented in Table 3. With the addition of these two tests, it would be possible to differentiate all of the species of the genus Yersinia on the basis of phenotypic characteristics, with the exception of $Y$. aleksiciae, which cannot be separated from $Y$. kristensenii based solely on phenotypic tests.

The results of the biochemical tests presented in Table 2 add new information about the biochemical diversity of $Y$. massiliensis strains and contribute to the further characterization of this species. Based on our results, a more detailed and broader description of the species $Y$. massiliensis is proposed and an emended description of this species is presented.

\section{Emended description of Yersinia massiliensis Merhej et al. 2008}

Yersinia massiliensis (mas.si.li.en'sis. L. fem. adj. massiliensis pertaining to Massilia, the ancient Roman name of Marseille, France, where the type strain was isolated).

Ferments cellobiose, trehalose, L-sorbose, maltose, Lfucose, salicin and D-xylose, but does not ferment methyl $\alpha$-D-glucoside. Raffinose and lactose fermentation reactions are variable. Positive reactions are obtained in tests for mucate utilization, nitrate reduction, pyrazinamidase production and aesculin hydrolysis. Motility at $37{ }^{\circ} \mathrm{C}$, gas production from glucose, lipase and $\mathrm{H}_{2} \mathrm{~S}$ production are negative. Citrate utilization is variable after incubation at $28{ }^{\circ} \mathrm{C}$ for 7 days. Arginine dihydrolase, lysine decarboxylase and phenylalanine deaminase activities are negative after incubation at $28{ }^{\circ} \mathrm{C}$ for $48 \mathrm{~h}$. Using API 20E strips (bioMérieux), positive results are reported for citrate utilization, arginine dihydrolase, lysine decarboxylase and phenylalanine deaminase after 24,48 and $72 \mathrm{~h}$ at $28{ }^{\circ} \mathrm{C}$ (Merhej et al., 2008).

The type strain is CCUG $53443^{\mathrm{T}}\left(=\mathrm{CIP} 109351^{\mathrm{T}}\right)$. This species has been isolated from the environment and food.

Table 3. Phenotypic differentiation of species of the genus Yersinia

Taxa: 1, Y. pestis; 2, Y. pseudotuberculosis; 3, Y. similis; 4, Y. enterocolitica; 5, Y. intermedia; 6, Y. frederiksenii; 7, Y. kristensenii; 8, Y. aleksiciae; 9, Y. aldovae; 10, Y. rohdei; 11, Y. mollaretii; 12, Y. bercovieri; 13, Y. ruckeri; 14, Y. entomophaga; 15, Y. massiliensis. Data are from Bockemühl \& Wong (2003), Ewing et al. (1978), Farmer et al. (1985), Sprague \& Neubauer (2005), Sprague et al. (2008) and Hurst et al. (2011) with additional information for $Y$. massiliensis based on the results from this study. Incubation was conducted at $28{ }^{\circ} \mathrm{C}$ for 7 days for carbohydrate fermentation and at $28{ }^{\circ} \mathrm{C}$ for $48 \mathrm{~h}$ for the other tests.,$+ \geqslant 90 \%$ strains positive;,$- \geqslant 90 \%$ strains negative; $\mathrm{v}$, variable, $11-89 \%$ of strains positive; ND, not done.

\begin{tabular}{|c|c|c|c|c|c|c|c|c|c|c|c|c|c|c|c|}
\hline Characteristic & 1 & 2 & 3 & 4 & 5 & 6 & 7 & $8^{*}$ & 9 & 10 & 11 & 12 & 13 & 14 & 15 \\
\hline Motility & - & + & + & + & + & + & + & + & + & + & + & + & $\mathrm{V}$ & + & + \\
\hline Urease production & - & + & + & + & + & + & + & + & + & $\mathrm{V}$ & + & + & - & - & + \\
\hline Indole production & - & - & - & $\mathrm{V}$ & + & + & $\mathrm{V}$ & $\mathrm{V}$ & - & - & - & - & - & - & + \\
\hline Citrate utilization & - & - & - & - & + & $\mathrm{V}$ & - & - & $\mathrm{V}$ & + & - & - & + & + & $\mathrm{V}$ \\
\hline Ornithine decarboxylase & - & - & - & + & + & + & + & + & + & + & + & + & + & + & + \\
\hline Mucate utilization & - & - & - & - & - & - & - & $\mathrm{ND}$ & - & - & - & - & - & $\mathrm{ND}$ & + \\
\hline \multicolumn{16}{|l|}{ Fermentation of: } \\
\hline Cellobiose & - & - & - & + & + & + & + & + & - & + & + & + & - & + & + \\
\hline Melibiose & $\mathrm{V}$ & + & - & - & + & - & - & - & - & $\mathrm{V}$ & - & - & - & + & - \\
\hline Raffinose & - & $\mathrm{V}$ & - & - & + & - & - & - & - & $\mathrm{V}$ & - & - & - & + & $\mathrm{V}$ \\
\hline L-Rhamnose & - & + & + & - & + & + & - & - & + & - & - & - & - & - & - \\
\hline
\end{tabular}

${ }^{\star} Y$. aleksiciae cannot be separated from $Y$. kristensenii based solely on phenotypic tests. 


\section{Acknowledgements}

We thank Fundação de Amparo à Pesquisa do Estado de São Paulo (FAPESP) (Proc. 06/51434-7) for financial support. During the course of this work R.A.S. was supported by a scholarship from FAPESP (Proc. 07/01146-8). We thank Dr Alzira Maria Paiva de Almeida from CpqAM/FIOCRUZ for providing the DNA for the two $Y$. pestis strains used in this study. We thank Dr Dimas Tadeu Covas (FMRP-USP) for coordinating the sequencing. We thank $\mathrm{Mr}$ Timothy Roberts (MSc), an English colleague, for reviewing the language.

\section{References}

Bockemühl, J. \& Wong, J. D. (2003). Yersinia. In Manual of Clinical Microbiology, 8th edn, pp. 672-683. Edited by P. R. Murray, E. J. Baron, J. H. Jorgensen, M. A. Pfaller \& R. H. Yolken. Washington, DC: American Society for Microbiology.

Bottone, E. J., Bercovieri, H. \& Mollaret, H. H. (2005). Genus XLI. Yersinia Van Loghem 1944, 15 ${ }^{\mathrm{AL}}$. In Bergey's Manual of Systematic Bacteriology, 2nd edn, vol. 2, pp. 838-848. Edited by D. J. Brenner, N. R. Krieg, J. T. Staley \& G. M. Garrity. New York: Springer.

Dempsey, A. M. \& Kitting, C. L. (1987). Characteristics of bacteria isolated from Penaeid shrimp. Crustaceana 52, 90-94. doi:10.1163/ 156854087 X00105.

Ewing, W. H., Ross, A. J., Brenner, D. J. \& Fanning, G. R. (1978). Yersinia ruckeri sp. nov., the Redmouth (RM) Bacterium. Int J Syst Bacteriol 28, 37-44. doi:10.1099/00207713-28-1-37.

Farmer, J. J., III, Davis, B. R., Hickman-Brenner, F. W., McWhorter, A., Huntley-Carter, G. P., Asbury, M. A., Riddle, C., Wathen-Grady, H. G., Elias, C. \& other authors (1985). Biochemical identification of new species and biogroups of Enterobacteriaceae isolated from clinical specimens. J Clin Microbiol 21, 46-76.

Farmer, J. J., III, Carter, G. P., Miller, V. L., Falkow, S. \& Wachsmuth, I. K. (1992). Pyrazinamidase, CR-MOX agar, salicin fermentationesculin hydrolysis, and D-xylose fermentation for identifying pathogenic serotypes of Yersinia enterocolitica. J Clin Microbiol 30, 2589-2594.

Hurst, M. R. H., Becher, S. A., Young, S. D., Nelson, T. L. \& Glare, T. R. (2011). Yersinia entomophaga sp. nov., isolated from the New Zealand grass grub Costelytra zealandica. Int J Syst Evol Microbiol 61, 844-849. doi:10.1099/ijs.0.024406-0.

Kandolo, K. \& Wauters, G. (1985). Pyrazinamidase activity in Yersinia enterocolitica and related organisms. J Clin Microbiol 21, 980-982.

Kotetishvili, M., Kreger, A., Wauters, G., Morris, J. G., Jr, Sulakvelidze, A. \& Stine, O. C. (2005). Multilocus sequence typing for studying genetic relationships among Yersinia species. J Clin Microbiol 43, 2674-2684. doi:10.1128/JCM.43.6.2674-2684.2005.

MacFaddin, J. F. (2000). Individual biochemical tests. In Biochemical Tests for Identification of Medical Bacteria, 3rd edn, pp. 3-453. Edited by L. McGrew. Philadelphia, PA: Lippincott Williams \& Wilkins.

Merhej, V., Adékambi, T., Pagnier, I., Raoult, D. \& Drancourt, M. (2008). Yersinia massiliensis sp. nov., isolated from fresh water. Int $J$ Syst Evol Microbiol 58, 779-784. doi:10.1099/ijs.0.65219-0.

Nicolle, P., Mollaret, H. H. \& Brault, J. (1976). [New results on the phage typing of Yersinia enterocolitica, concerning more of 4000 strains of various origins (author's translation)]. Rev Epidemiol Sante Publique 24, 479-496.

Souza, R. A., Pitondo-Silva, A., Falcão, D. P. \& Falcão, J. P. (2010). Evaluation of four molecular typing methodologies as tools for determining taxonomy relations and for identifying species among Yersinia isolates. J Microbiol Methods 82, 141-150. doi:10.1016/ j.mimet.2010.05.005.

Sprague, L. D. \& Neubauer, H. (2005). Yersinia aleksiciae sp. nov. Int J Syst Evol Microbiol 55, 831-835. doi:10.1099/ijs.0.63220-0.

Sprague, L. D., Scholz, H. C., Amann, S., Busse, H.-J. \& Neubauer, H. (2008). Yersinia similis sp. nov. Int J Syst Evol Microbiol 58, 952-958. doi:10.1099/ijs.0.65417-0.

US Food and Drug Administration (2010). BAM Media M105: mucate broth. Accessed 24 March 2010. http://www.fda.gov/Food/Science Research/LaboratoryMethods/BacteriologicalAnalyticalManualBAM/ UCM064081

Wanger, A. (2007). Yersinia. In Manual of Clinical Microbiology, 9th edn, vol. 1, pp. 688-697. Edited by P. R. Murray, E. J. Baron, J. H. Jorgensen, M. L. Landry \& M. A. Pfaller. Washington, DC: American Society for Microbiology.

Wauters, G., Aleksić, S., Charlier, J. \& Schulze, G. (1991). Somatic and flagellar antigens of Yersinia enterocolitica and related species. Contrib Microbiol Immunol 12, 239-243. 